\title{
Study the beneficial activity of low level laser in experimentally induced pain in mice
}

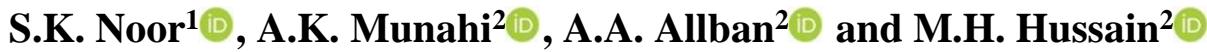 \\ ${ }^{1}$ Department of Basic Sciences, College of Dentistry, ${ }^{2}$ College of Veterinary Medicine, Department of Surgery and Obstetrics, \\ University of Al-Qadisiyah, Al-Qadisiyah, Iraq
}

\begin{tabular}{l} 
Article information \\
\hline Article history: \\
Received May 30, 2020 \\
Accepted August 03, 2020 \\
Available online June 27, 2021 \\
\hline Keywords: \\
Analgesia \\
LASER \\
Mice \\
Pain \\
\\
\hline Correspondence: \\
A.A. Allban \\
abbas.ali@ qu.edu.iq
\end{tabular}

\begin{abstract}
Low-level laser therapy (LLLT) was applied to alleviate pain with minimal adverse effects. This study was conducted to evaluate the analgesic effects of low-level laser therapy for pain control to help in surgical and emergency cases. The present study has demonstrated these effects experimentally on forty-five male albino mice weighing $45 \pm 5$ grams. Creation of pain in animals was done by injection of $50 \mu 1$ of $5 \%$ formalin into the left posterior paw. Lifting of the paw was considered as an indicator of the pain. All animals were divided into 3 groups 15 mice in each group. In group A the LLLT $820 \mathrm{~nm} .200 \mathrm{mw}, 48 \mathrm{~J} / \mathrm{cm} 2$ was focused on the affected paw for 1 min. In group B a diode laser with same dose in group A and different time used to irradiate the injected paw continuously for 30 seconds. The group C (control group); the laser probe was placed over the affected paw for concurrent but the apparatus was switched off. The results demonstrated that there were significant differences between group A and B when compared with group C during the 5 minutes as well as in 10 minutes and 15 minutes. Group A also registered a superior analgesic effect when compared with group B. Groups of LLLT were better than those found for control one and the irradiation continuous for one minute was better than 30 seconds at 5,10 and 15 minutes after the creation of pain.
\end{abstract}

DOI: $10.33899 /$ ijvs.2020.127228.1487, (C2021, College of Veterinary Medicine, University of Mosul.

This is an open access article under the CC BY 4.0 license (http://creativecommons.org/licenses/by/4.0/).

\section{Introduction}

The classical definition of pain can be defined as sensory and emotional changes associated with damage or disruption of the tissue (1). Clinically, pain can be acute or chronic, the first type is a preventative or repulsive condition that the body takes to warn of an individual's exposure to a specific condition that involves direct injury to the body and requires urgent preventive measures. While chronic pain includes a permanent or intermittent condition and differs from acute pain not only because of its appearance and duration but more in its mechanisms (2). chronic pain may not have identifiable ongoing injury or inflammation, and often responds poorly to anti-inflammatory drugs (3). Injecting of the formaldehyde solution into the left posterior paw of the mice causes two stages of pain-causing behavior, the first phase involves five minutes of direct chemo-induced stimulation of nociceptive peripheral afferent fibers, which release prophylactic peptides, such as bradykinin and substance, and release the harmful stimulus, the secondary stage lasts from 15 to 30 minutes and triggers the release of inflammatory mediators such as histamine, prostaglandin, serotonin, bradykinin or hypersensitization to the spinal cord in the first stage (4). Low-level laser (light) therapy (LLLT) and LED (light emitting diode) therapy (also known as photobiomodulation) is a proper method to diminish postoperative pain due to its safe, painless, noninvasive technique recently, the Food and Drug Administration approved LLLT for the relief of pain, later it was suggested that laser therapy can produce biomodulation of enzymatic, photochemical and photophysical activities by the liberation of photons which absorbed by the cell of radiated tissue (5). 
An experimental study had proposed radiation may interfere with the pituitary hypothalamus adrenal axis, it was suggested radiation can protect the cell against nitric oxideinduced cell death (6). The action of reduction of inflammation and edema because of the cessation of prostaglandin synthesis causes inhibition of prostacyclin and an increase in blood flow as well as peripheral nerve action (7). The important factor in pain relief after laser therapy is increased blood flow because it increases the oxygenation, the activity of neutrophils, macrophages, fibroblasts, lymphatic drainage, and damaged or defective cell metabolism (8). Mitochondria are also proposed to be the site for the laser effect, resulting in an increment of production of ATP, induction of transcription factors, these effects lead to an increment of cell proliferation and fibroblast migration, reduction of cytokines, inflammatory mediator and reduced pain and improved wound healing $(9,10)$. The dose and wavelength are the important factors in laser therapy and their variations can stimulate certain effects as the synthesis of ATP and many clinical and experimental studies showed the effectiveness of LLLT for the relief of chronic pain (11).

The aim of this study was to evaluate the analgesic effects of low-level laser therapy for pain control to help in surgical and emergency cases.

\section{Material and methods}

The study was carried out on forty-five male mice weighing from 40 to 50 grams and clinically healthy. The mice were fed on diet and water ad libitum and were divided into three groups. Fifteen animals were assigned randomly for each groups. The method of creation of pain in the animals was modified from (12) and done by injection of 50 $\mu \mathrm{l}$ of $5 \%$ formalin into the left posterior paw of the animals placed in a glass enclosure. During the five minutes prior to the procedure of creation of pain; each animal was adapted to the testing cylinder glass for habituation. The chemical material (formalin) urged lifting of the posterior paw which was regarded as an indicator of the behavior of pain.

A stopwatch was used to record the total time which was spent on lifting the paw with formalin injection. The initial nociceptive response was registered as early as five minutes in the early phase after injection of formalin and ten minutes as well as fifteen minutes after formalin injection in the late phase. The proposed analgesic technique which used was laser diode rays. In group A, the low-level laser diode $(820 \mathrm{~nm}) 200 \mathrm{mw}, 48 \mathrm{~J} / \mathrm{cm}^{2}$ operating in continuous wave used to irradiate the points after the formalin injection by direct contact for one minute. In group B a diode laser (820nm) $200 \mathrm{mw}, 48 \mathrm{~J} / \mathrm{cm}^{2}$ continuously was used to irradiate the injected paw by direct contact for 30 seconds. Related to group $\mathrm{C}$, the control group, the laser probe was put on the planter pad as in the previous groups and stay for the same time, but the apparatus was switched off. Immobility of animals by head restraint during the application of laser was done for all groups. After application of laser over the planter pad; immediately injection of $50 \mu \mathrm{l}$ in $5 \%$ formalin subcutaneously with an insulin syringe, after that the animals were kept in an individual glass cylinder with a mirror on the floor to facilitate visualization of the mice paws. One measurement evaluator and one observer measuring the time for each animal when was lifting the left hind paw, a stopwatch was started each time the mouse lifted its left hind paw and stopped at the moment the paw reached contact with the mirrored floor of the cylinder. The added partial time of lifting the left hind paw was recorded five, ten and fifteen minutes. Results were indicated as the mean number of lifting time (seconds) $\pm \mathrm{SE}$ at the observation time of five, ten, fifteen minutes were made by analysis variance (ANOVA). A P-value of less than 0.05 was regarded as significant.

\section{Ethical approval}

All experimental procedures on mice were agreed by the Ethics Committee in the College of the Veterinary Medicine, University of Al-Qadisiyah.

\section{Results}

All spontaneous behavior of indicating pain after subcutaneous injection of formation in the left hind paw of the animals were recorded. Table 1 showed the significant differences between group A and B when compared with control group $C$ and they recorded $97 \pm 8.23,127.66 \pm 3.72$ and $184.83 \pm 6.88$ respectively during the first five minutes. Whereas group A gave the best outcome. In the 10 minutes after injection of formation, group A and B also showed significant differences in comparison with the control group where registered $61.33 \pm 7.72,70 \pm 9.85$ and $179.66 \pm 4.14$ respectively. Similarly, in the fifteen minutes, group A and group B clarified significant differences when compared with group $\mathrm{C}$ where registered $29.66 \pm 5.78,66 \pm 3.01$ and $148.66 \pm 4.02$ respectively.

Table 1: Analgesic action of laser in two levels in mice

\begin{tabular}{lccc}
\hline \multirow{2}{*}{ Groups } & \multicolumn{3}{c}{ Time of reading analgesia in minutes } \\
\cline { 2 - 4 } & First 5 minute & 10 minute & 15 minute \\
\hline \multirow{2}{*}{$\mathrm{A}$} & $97 \pm 8.23$ & $61.33 \pm 7.72$ & $29.66 \pm 5.78$ \\
& $\mathrm{Ba}$ & $\mathrm{Bab}$ & $\mathrm{b}$ \\
$\mathrm{B}$ & $127.66 \pm 3.72$ & $70 \pm 9.85$ & $66 \pm 3.01$ \\
& $\mathrm{Ba}$ & $\mathrm{Ba}$ & $\mathrm{Ba}$ \\
$\mathrm{C}$ & $184.83 \pm 6.88$ & $179.4 \pm 4.14$ & $148.66 \pm 4.02$ \\
& $\mathrm{Aa}$ & $\mathrm{Aa}$ & $\mathrm{Aa}$ \\
\hline
\end{tabular}

Figure 1 indicated that the data of group A at the five minutes had registered $97 \pm 8.23$ significant differences when compared with a group of 15 minutes $29.66 \pm 5.78$ respectively. The control group in the three registered intervals had no significant differences among the recorded 
values where record $184.83 \pm 6.88,179.4 \pm 4.14$ and 148.66 \pm 4.02 respectively. Similarly, group B showed that there was no significant difference recorded during the five, ten and fifteen minutes $127.66 \pm 3.72,70 \pm 9.85$ and $66 \pm 3.01$ respectively.

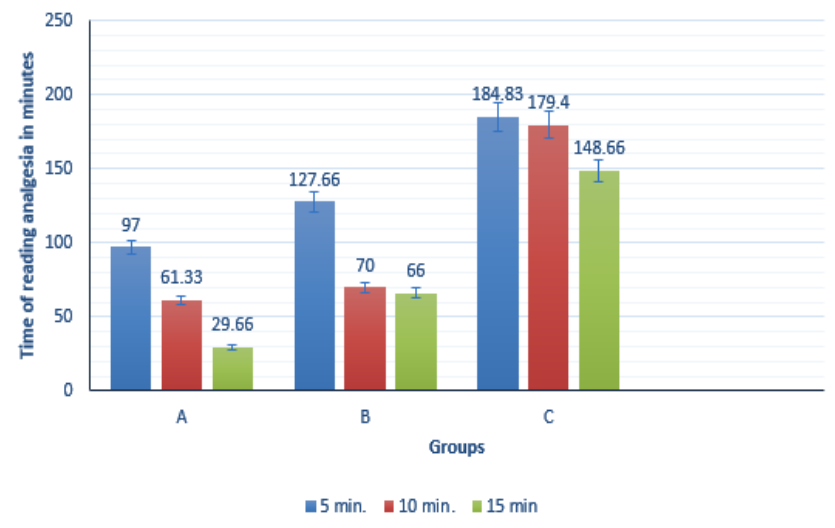

Figure 1: Analgesic action of laser in two levels in mice.

\section{Discussion}

Three different kinds of pain have been proved, central, neuropathic and nociceptive. The central one has not yet been confirmed to be treated by LLLT (13). Clinical studies demonstrated that LLLT could treat nociceptive pain (14) as well as neuropathic pain (15). Pain is a familiar symptom that can be markedly weakened. Although the precise mechanism is not well known, low-level laser therapy shows efficacy in treating patients with different syndromes and forms of pain, especially in musculoskeletal disorders (16). This has been achieved by the present study where the results showed that low-level laser therapy has a proportional effect most likely to be produced by stimulating peripheral opioid receptors by releasing self- opioids cells from inflammatory cells. These data suggest that peripheral opioids have actively participated in the analgesic mechanism in low-level laser therapy. A recent study (17) showed that the therapeutic effects of the 660-nm laser wavelength have better effects than the laser with a wavelength of $980 \mathrm{~nm}$. Several types of research of evidence support the above-mentioned hypothesis. The Low-level laser enables the expression of beta-endorphins without the high accumulation of inflammatory cells. The $\beta$ Endorphins have a strong analgesic effect (18). In our results, the low-level laser therapy indicates analgesia at the onset of inflammation by a peripheral opioid mechanism as suggested by (19) who found that the low-level laser therapy may enable the peripheral endogenous opioid analgesia. The formaldehyde which used in the present study is $5 \%$ due to the solution of formalin with a concentration lower than $2 \%$ cannot be sufficient in the production of pain responses in mice tissue (20).
The laser used in this study was $48 \mathrm{~J} / \mathrm{cm}^{2}$, while the other studies mention that the dose $10 \mathrm{~J} / \mathrm{cm}^{2}$ or even $7 \mathrm{~J} / \mathrm{cm}^{2}$ can give good effect, although the source of laser production is different, they used red light wavelength or infrared laser (21) and they submitted the irradiation directly on the tissues. Other factors should be considered such as constant blood flow and thickness of animal tissue. When there is no accuracy in application, the high laser doses can cause damage of tissues (22). Contrarily, low doses may not induce biological effects on irradiated tissues as found by (23) who noted that low doses of $\mathrm{HeNe}$ laser on the circulation of rats with $1 \mathrm{~J} / \mathrm{cm}^{2}$ can't cause any beneficial effects.

Low-level laser therapy enhances elevation in the synthesis and liberation of endorphins and decreases the release of pain receptors as serotonin and bradykinin to treat different types of bruising conditions (6). We thought that reduction in sensory nerve conduction by application of laser is one of the important mechanisms of relief pain in mice. Such possible actions were reported by (24) who mention that the cell membranes stabilization can be regulated by transmissions of the nerve impulses. This regulation deactivates depolarization by elevation in ATP synthesis, which causes an increase in latency of nerves. When there is a reduction in the velocity of sensory nerve conduction, the relied pain is noticed (21).

Our results have been agreed with (25) which found that the other major factor in the pain associated with laser therapy in animals compared with the control group is the vascular effects of the laser which are explained by increased blood flow that will raise oxygen, neutrophil activity, cattle phages and fibroblasts, lymphatic drainage and metabolism of defective cells is responsible for pain relief after the first onset of irradiation of tissue.

Low-level laser results in a photochemical faster effect due to direct action on mitochondria. In our study the peak pain was sustained up to 15 minutes for animals in all groups, in control groups, the mouse also begins to raise the left-hand paw, which indicates pain, but the treatment groups keep hind paw up for a shorter time. This was because of better analgesic effect of low laser therapy in the first time periods after its irradiation. The observation of animal behavior clarified a pain peak at 5,10 and 15 minutes after the injection of formalin, in group A shows the best results due to the long exposure dose of laser which is along one minute and this give good results related with analgesic effect and agreed with (25) who approved that the wavelength and dose are important factors in laser therapy. We concluded that the therapeutic low-level laser can reduce such discomfortable sensation of pain due to its effect on healthy tissue of the paw, as presented in this study.

\section{Conclusions}

The results of this study showed that the low-level laser therapy groups were better than those found for control one 
and the irradiation continuous for one minute was better than 30 seconds at 5,10 and 15 minutes after the creation of pain which proof the hypothesis of the analgesic effect of LLLT.

\section{Acknowledgement}

The authors would like to thank the staff of medical basic sciences laboratory College of dentistry university of AlQadisiyah.

\section{Conflict of interest}

The authors affirm that they had no competing interests.

\section{References}

1. Hermanussen S, Do M, Cabot PJ. Reduction of beta endorphincontaining immune cells in inflamed paw tissue corresponds with a reduction in immune-derived antinociception: Reversible by donor activated lymphocytes. Anesth Analg. 2004;98:723-729. DOI: 10.1213/01.ANE.0000099369. 23397.D7

2. Aljobory AI, Jaafar S, Ahmed AS. Using acupuncture and electroacupuncture in the treatment of laminitis in racing horses: a comparative study. Iraqi J Vet Sci. 2021;35(1):15-21. DOI: 10.33899/ijvs.2019.126217.1263

3. Wang LX, Wang ZJ. Animal and cellular models of chronic pain. Advance Drug Deliver Rev. 2003;55:949-65. DOI: 10.1016/S0169409X(03)00098-X

4. Granados-Soto V, Arguelles CF, Alvarez-Leefmans FJ. Peripheral and central antinociceptive action of $\mathrm{Na}^{+}-\mathrm{K}^{+}-2 \mathrm{Cl}$ - cotransporter blockers on formalin-induced nociception in rats. Pain. 2005;114:231-8. DOI: 10.1016/j.pain.2004.12.023

5. de Oliveira RF, de Andrade Salgado DM, Trevelin LT, Lopes RM, da Cunha SR, Aranha AC, de Paula Eduardo C, de Freitas PM. Benefits of laser phototherapy on nerve repair. Lasers Med Sci. 2015;30:1395-06. DOI: 10.1007/s10103-014-1531-6

6. Shirin F, Talieh M, Reza S. Biological effects of low level laser therapy. J Lasers Med Sci. 2014;5:58-62. [available at]

7. Tomaz de Magalhaes M. Light therapy modulates serotonin levels and blood flow in women with headache. A preliminary study. Exp Biol Med. 2016;241:40-45. DOI: 10.1177/1535370215596383

8. Schindl A, Heinze G, Schindl M, Pernerstorfer-Schön H, Schindl L. Systemic effects of low-intensity laser irradiation on skin microcirculation in patients with diabetic microangiopathy. Microvasc Res. 2002;64:240-6. DOI: 10.1006/mvre.2002.2429

9. Shaban KhA, Ibrahim MH, Faris GA, Al-zubaidy MH. Evaluation of the antinociceptive effect of xylazine and it's interaction with metoclopramide in the acute pain model in mice. Iraqi $\mathrm{J}$ Vet Sci. 2020;34:383-388. DOI: 10.33899/ijvs.2019.126070.1226

10. Jameel AH, Mohammed MJ, Mahdi MS, Thalj KM. Physiological effects of lactic acid bacteria against melamine induced toxicity in female albino rats. Iraqi J Vet Sci. 2021;35:1-7. DOI: 10.33899/ijvs.2020.126183.1259

11. Masoumipoor M, Jameie SB, Janzadeh A, Nasirinezhad F, Soleimani M, Kerdary M. Effects of 660- and 980-nm low-level laser therapy on neuropathic pain relief following chronic constriction injury in rat sciatic nerve. Lasers Med Sci. 2014;29:1593-8. DOI: 10.1007/s10103014-1552-1

12. Al-Chalabi AS, Asim R, Rahim H, Malek FA. Evaluation of the thermal effect of LTE $2600 \mathrm{MHz}$ (4G) electromagnetic field (EMF) exposure: Thermographic study on rats. Iraqi J Vet Sci. 2020;35:279-285 DOI: 10.33899/ijvs.2020.126787.1379

13. Howard BC, Roberta TC, Michael R, Hamblin JC. The use of low level laser therapy (LLLT) For Musculoskeletal Pain. MOJ Orthop Rheumatol. 2015; 2. DOI: 10.15406/mojor.2015.02.00068
14. Nesioonpour S, Mokmeli S, Vojdani S, Mohtadi A, Akhondzadeh R. The effect of low-level laser on post-operative pain after tibial fracture surgery: A double-blind controlled randomized clinical trial. Anesth Pain Med. 2014;4: DOI: 10.5812/aapm. 17350

15. Falaki F, Nejat AH, Dalirsani Z. The effect of low-level laser therapy on trigeminal neuralgia: A review of literature. J Dent Res Dent Clin Dent Prospects. 2014; 8:1-5. DOI: 10.5681/joddd.2014.001

16. Chen J, Huang Z, Ge M, Gao M. Efficacy of low-level laser therapy in the treatment of TMDs: a meta-analysis of 14 randomized controlled trials. J Oral Rehabil. 2015; 42:291-9. DOI: 10.1111/joor.12258

17. Masoumipoor M, Jameie SB, Janzadeh A, Nasirinezhad F, Soleimani M, Kerdary M. Effects of 660- and 980-nm low-level laser therapy on neuropathic pain relief following chronic constriction injury in rat sciatic nerve. Lasers Med Sci. 2014;29:1593-98. DOI: 10.1007/s10103-014-1552-1

18. Hartwig AC. Peripheral beta-endorphin and pain modulation. Anesth Prog. 1991;38:75-78. [available at]

19. Hagiwara S, Iwasaka H, Okuda K. GaAlAs $(830 \mathrm{~nm})$ low-level laser enhances peripheral endogenous opioid analgesia in rats. Lasers Surg Med.2007; 39:797-802. DOI: 10.1002/1sm.20583

20. Saddi G, Abbott FV. The formalin test in the mouse: A parametric analysis of scoring properties. Pain. 2000;15;89:53-63. DOI: 10.1016/S0304-3959(00)00348-1

21. Ebert DW, Roberts C. In vitro frog sciatic nerve as a peripheral nerve model for studies of the mechanism of action of low energy lasers: Part one. Lasers Surg Med.1997;21:32-41. DOI: 10.10021096-910121:1

22. Hawkins D, Abrahamse H. Biological effects of helium-neon laser irradiation on normal and wounded human skin fibroblasts. Photomed Laser Surg.2005; 23:251-9. DOI: 10.1089/pho.2005.23.251

23. Núñez SC, Nogueira GE, Ribeiro MS, Garcez AS. Lage-Marques JL. He-Ne laser effects on blood microcirculation during wound healing: a method of in vivo study through laser Doppler flowmetry. Lasers Surg Med. 2004;35:363-8. DOI: 10.1002/1sm.20109

24. Iijima K, Shimoyama N, Shimoyama M, Mizuguchi T. Evaluation of analgesic effect of low-power He: Ne laser on post herpetic neuralgia using VAS and modified McGill pain questionnaire. J Clin Laser Med Surg. 1991;9:121-6. DOI: $\underline{10.1089 / \mathrm{clm} .1991 .9 .121}$

25. Hakgüder A, Birtane M, Gürcan S, Kokino S, Turan FN. Efficacy of low level laser therapy in myofascial pain syndrome: an algometric and thermographic evaluation. Lasers Surg Med. 2003;33:339-43. DOI: $\underline{10.1002 / 1 \mathrm{sm} .10241}$
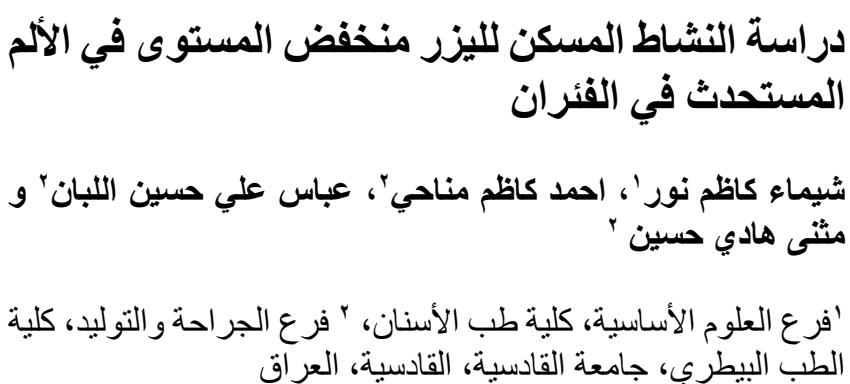

الخلاصة

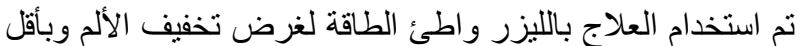

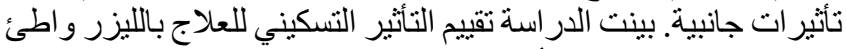

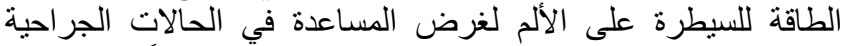

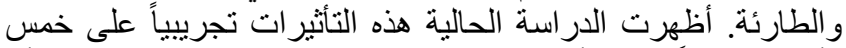

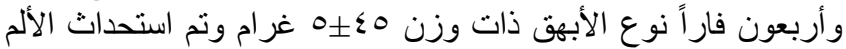

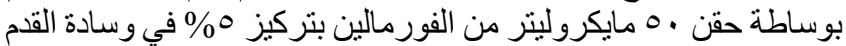

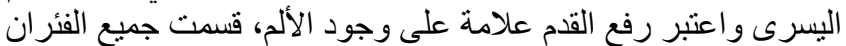
إلى ثلاثة مجاميع 10 فأر أ في كل مجمو على في المجمو عة أ كانت جرعة الفران 
المجموعة أو ب ب عند المقارنة بالمجموعة ج خلال الفترة الزمنية هو و

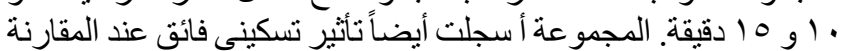

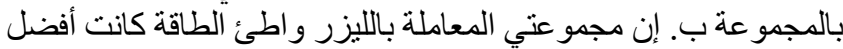

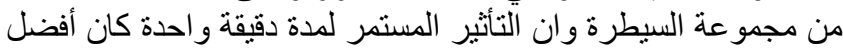

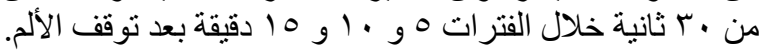

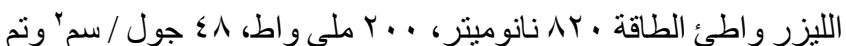

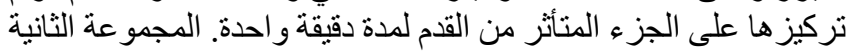

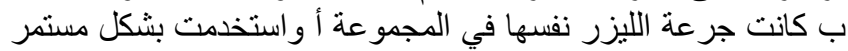

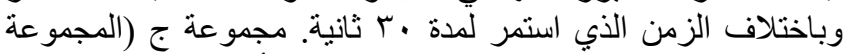

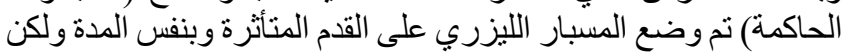
الجهاز مفصول عن الطاقة. بينت النتائج وجود فرقائرة فرنفي معنوي بين 